\title{
Historical Aspects of Eosinophilic Esophagitis: From Case Reports to Clinical Trials
}

\author{
Stephen Attwood Shariq Sabri \\ Department of Surgery, Durham University, Durham, and North Tyneside General Hospital, North Shields, UK
}

\author{
Key Words \\ Eosinophilic esophagitis · Case series · Clinical trials . \\ Diagnosis · Pathophysiology
}

\begin{abstract}
Eosinophilic esophagitis (EoE) is a clinicopathological condition characterized clinically by symptoms of esophageal dysfunction in the absence of acid reflux, with typical endoscopic findings and eosinophilia on biopsy. This article looks into the historical clinical recognition and description of EoE, in particular clinical manifestations, natural history, and epidemiology. Additionally, the evolution of endoscopic recognition and development of clinical trials are described: EoE is an isolated disease of the esophagus, although it is associated with other antigen-driven diseases such as asthma, rhinitis, and atopic dermatitis. After initial case reports which were mostly not typical of the disease state now described, the first case series were described in 1993 and 1994 in adults, and 1995 in children. Although rarely seen before 2000 , the disease is now commonly recognized. Randomized clinical trials have now been performed on topical steroids, and on biological agents targeted against IL-5, IL-13, and other mediators. Therapy with dilatation may be best guided by measures of compliance and distensibility. Work is needed on biomarkers of the disease's severity and progression, and predictive indexes of complications. EoE is a relatively new disease of increasing importance. It represents an important diagnosis in patients with upper gastro-
\end{abstract}

intestinal symptoms and must be considered in all patients with dysphagia where the diagnosis is not certain and in all patients who have an assumed diagnosis of reflux but are not responding to standard reflux therapy.

(c) 2014 S. Karger AG, Basel

\section{Introduction}

The identification of a distinct disease termed esophageal eosinophilia or eosinophilic esophagitis (EoE) with its own clinical characteristics (dysphagia in adults and regurgitation and feeding difficulties in young children) and separate from reflux injury or other known diseases was described in the early 1990s. Prior to this, descriptions of esophageal eosinophils were single case reports and associated with a variety of disorders without any specific disease pattern. This paper will describe the milestones in the development of our understanding of EoE including the initial case report, the first case series, the first description of natural history, and the development of therapies. There have been relatively few randomized clinical trials, but the development of international consensus guidelines has been an important step which has helped to standardize the diagnostic and therapeutic approach.

In 1978, Landres et al. [1] reported an isolated case of vigorous achalasia in a patient with marked hypertrophy and eosinophilic infiltration of esophagus. They conclud-

\section{KARGER}

E-Mail karger@karger.com

www.karger.com/ddi (c) 2014 S. Karger AG, Basel

0257-2753/14/0322-0034\$39.50/0
Prof. Stephen Attwood

North Tyneside General Hospital

Rake Lane, North Shields NE29 8NH (UK)

E-Mail Stephen.Attwood@nhct.nhs.uk 
ed that this was a variant of eosinophilic gastroenteritis which predisposed to esophageal motor disorder. This case had no other features of what we now recognize as EoE. It is still unusual to discover any excess of eosinophils in patients with achalasia or other defined motor disorders of the esophagus.

In 1981, Picus and Frank [2] reported a case of a 16-year-old boy with progressive dysphagia for 1.5 years. Endoscopic findings were suggestive of multiple $1-\mathrm{mm}$ nodular filling defects in the esophagus in an area of stricture with dilatation above. Radiology showed a luminal narrowing, wall rigidity, and high circulating eosinophil count. The authors assumed it was a variant of eosinophilic gastroenteritis. Similarly, Münch et al. [3] (1982) and Matzinger and Daneman [4] (1983) both described isolated cases of esophageal eosinophilia with dysphagia in patients with assumed eosinophilic gastroenteritis. In 1985, Feczko et al. [5] reported 3 cases of eosinophilic infiltration of esophagus, with 2 of the patients showing eosinophilic gastroenteritis. Two out of 3 patients developed esophageal stricture secondary to submucosal fibrosis. The author did not clarify any etiology and assumed reflux was involved, but in retrospect these were probably EoE. Lee [6] in 1985 reported eosinophilic infiltration in esophageal mucosal biopsy in 11 patients with average age of 14.6 years - these patients had reflux symptoms and their eosinophil density was low. In retrospect, these were probably patients with gastroesophageal reflux disease (GERD).

In 1993, Attwood et al. [7] reported 12 adults with dysphagia, normal $\mathrm{pH}$ monitoring, and dense esophageal eosinophilia [ $>20$ eosinophils/high-power field (HPF)]. Importantly, control patients with proven GERD had a mean of 3.3 eosinophils/HPF in their esophageal mucosa. Seven patients had food hypersensitivity, and all required advanced intervention (dilatation and/or steroids in 1 case) for resolution of symptoms. The following year, Straumann et al. [8] described a series of 10 patients with acute recurrent dysphagia seen over a 4 -year period who showed discrete endoscopic changes and high concentrations of epithelial esophageal eosinophils treated with systemic steroids and antihistamines. The first publication in children was by Kelly et al. [9] in 1995, and they identified 10 children who were diagnosed on clinical and histological grounds to have EoE. Six out of those 10 had been subject to antireflux therapy without any symptomatic improvement. Two of these patients had already received fundoplication, and all responded well to amino acid formulas, suggesting an allergic etiology. The characteristics in pediatric EoE appeared to reflect greater

EoE - From Case Reports to Clinical Trials amounts of regurgitation and failure to thrive, while the typical presentation in adults with EoE was dysphagia and food impaction.

Following these initial case series, very little progress was apparent in the literature for the next 8-10 years until the description in 2003 of the chronic nature of the natural history of EoE. Straumann et al. [10] described the longest follow-up of 30 adults with EoE [ 22 men, mean age: 40.6 years (range: $16-71$ )]. The presenting symptom was almost exclusively dysphagia with food impaction, and diagnosis was delayed an average of 4.6 years (range: $0-17)$. During the follow-up period of 1.4-11.5 years, $23 \%$ of the patients reported increasing dysphagia and $36.7 \%$ reported stable symptoms. No change in endoscopic features was identified in 6 of the 7 patients in whom a subepithelial component could be analyzed, but an increase in fibrosis and thickening was documented.

Although a therapy with topical steroids had been described in children in 1998 [11], 2003 saw the therapies become established in adults by Arora et al. [12], and the use of montelukast medication was described by Attwood et al. [13] in the same year. These options now gave some direction to the therapy in addition to dilatation of strictures. Following these publications there was a rapid rise, almost logarithmically, with many hundreds of reports being published annually. From descriptions in the years 2003-2008 it became clear that there were a range of endoscopic phenotypes of EoE. Although not initially recognized, the patterns of linear furrows, circular ridges and more defined rings (trachealization), the presence of white microabscesses, and the complication of severe strictures in some were all manifestations of EoE $[14,15]$. It is still not clear why EoE presents in these different phenotypes or whether they signify a different prognosis or disease pattern of responsiveness to therapy. During the years 2004-2006, 8 additional case series were described in multiple geographic locations (table 1) [16-23]. The total number of patients remained small, amounting to $<300$ reported patients, until after 2007 when case series with $>300$ patients began to appear. The central pathology laboratories in the USA are now aggregating information on $>14,000$ patients with this condition, indicating how frequently this disease is now recognized.

The development of international consensus guidelines has been a very important milestone in EoE, especially in the absence of good randomized controlled data on the therapy and outcome of care. The 2007 guideline of the American Gastroenterology Institute [24] was very helpful in defining the disease, and the update in 2011 [25] has provided detail on the value of investigations, the 
Table 1. Rapid rise in the size and frequency of case series reported worldwide (2004-2006) and reported just from the USA and UK (2008-2010)

\begin{tabular}{lc}
\hline Worldwide, 2004-2006 & 259 patients \\
\hline Gonsalves et al. [15] & 74 \\
Mueller et al. [23] & 30 \\
Remedios et al. [16] & 26 \\
Parfitt et al. [17] & 41 \\
Villarín et al. [18] & 9 \\
Potter et al. [19] & 29 \\
Straumann et al. [50] & 30 \\
Desai et al. [32] & 17 \\
\hline UK and USA, 2008-2010 & 538 patients \\
\hline Kanakala et al. [20] & 38 \\
Alexandrapoulou et al. [51] & 21 \\
Collins et al. [52] & 59 \\
Assa'ad et al. [53] & 57 \\
Kapel et al. [21] & 363 \\
\hline
\end{tabular}

Case series now being collated include $>10,000$ patients in the USA [15-23].

current therapies, and the development of complications, particularly stricture and perforation. EoE is now the commonest cause of spontaneous perforation of the esophagus, although it is usually a partial perforation, and treated differently to the original complete disruption originally described by Boorhaeve. In 2008, 15 years after the first case series was published, the condition finally gained an ICD-9 classification: 530.13.

A key feature in managing patients with EoE is to understand that they are not suffering GERD. Low concentrations of esophageal eosinophils are commonly seen in GERD, but these usually only amount to $1-5 / \mathrm{HPF}$. It is also not clear how common eosinophils are present in a normal population, but the study of Ronkainen et al. [26] (2007) in the Swedish town of Kalixanda is very revealing. They showed that in 1,000 randomly chosen subjects, $0.1 \%$ of the population had eosinophil concentrations of $>20 / \mathrm{HPF}$ and $0.2 \%>15 / \mathrm{HPF}$ on biopsy $2 \mathrm{~cm}$ above the $\mathrm{ZE}$ line. Thus, EoE was extremely rare in a normal population. In some clinical series of EoE, higher rates of reflux are documented [27-29], but these studies are confounded by the fact that the centers are reference centers for GERD and thus the referral population in those centers is not representative of the wider population. We looked at the frequency of EoE in a confirmed GERD population as part of a randomized controlled trial of medical and sur- gical therapy in the LOTUS trial $[30,31]$ and took biopsies when the patients were off medication for 7 days. Out of 541 patients, only 7 had concentrations of epithelial eosinophils $>20 / \mathrm{HPF}$, and an additional 3 had concentrations of epithelial eosinophils $>15 / \mathrm{HPF}$. The total incidence of EoE by simple counting of eosinophils in that reflux population was $1.8 \%$ - not dissimilar to the normal population of Kalixanda. According to Lee et al. [22], the diagnosis of EoE is more than just counting eosinophils, as it involves other biological changes such as increased extracellular major basic protein deposition in the esophageal mucosa of EoE, which is not seen at all in patients with GERD [32].

Hirano [33] recently reemphasized the need to perform biopsies while the patient is on proton pump inhibitors in order to refine the diagnosis and treatment of EoE to fit recent guidelines. While a subset of GERD patients may have high eosinophil counts and respond to proton pump inhibitors (the proton pump inhibitor-sensitive phenotype), these patients do not fit the diagnosis of EoE and present little therapeutic challenge.

Distinguishing EoE from GERD is very important in order to prevent years of ineffective treatment in nonrefluxing patients. The extreme cases are those subject to antireflux surgery for EoE; a number of case reports have shown this is more common in children. The original description of Kelly et al. [9] had 2 such patients, and our own report, Lamb et al. [34], was of a 12-year-old boy with a tight upper esophageal stricture who did not improve after Nissen fundoplication. Five years later, following accurate diagnosis, he responded fully to topical steroids and dilatation. Having not eaten anything solid for 10 years, he then enjoyed a completely normal diet. This severity of quality of life restriction by EoE is sometimes quite alarming, and the value of an accurate diagnosis and effective therapy is equally dramatic.

\section{Pathophysiology}

Over the past 10 years there have been huge strides in understanding the immunology and pathophysiology of EoE. This has raised expectations of effective immunebased treatments. Other papers in this volume focus on this area, which now has a huge wealth of information, and it is expected that this will provide avenues to research new drug treatments. The reasons why dysphagia occurs is clear in those with stricture, but not clear in some patients who just have linear furrows, or with microabscesses [35]. It is unlikely that the dysphagia is re-
36

Dig Dis 2014;32:34-39

DOI: $10.1159 / 000357007$
Attwood/Sabri 
lated to motility disorder, but more likely that it is due to stiffness in the submucosal, or perhaps muscular, layers of the esophageal wall. It is now feasible to measure the compliance of the esophageal wall using impedance planimetry (EndoFLIP) [36], and this may be a great help in identifying which patients would benefit from dilatation, and which levels of the esophagus require dilatation and by how much.

\section{Randomized Clinical Trials}

Despite huge strides in our knowledge, the development of new treatment strategies through randomized clinical trials has been relatively slow. The main therapy with proven benefit, topical steroids, has produced some confounding results. Placebo-controlled trials of budesonide have shown its effectiveness [37], and placebo-controlled trials of oral viscous budesonide in children [38] have been conclusive. However, these well-conducted studies reveal a difference between symptom benefit and clearance of histological abnormality: medium doses of steroids produce the most effective symptom benefit but do not clear epithelial infiltration with eosinophils, while the highest doses of topical budesonide can abolish intraepithelial eosinophils but not improve the overall symptom benefit. It is not understood why symptom improvement can occur without eosinophil clearance, and it remains to be worked out if this has a bearing on the development of long-term complications such as fibrosis and stricture.

The second major drug group in EoE therapy are the biological modifiers involved in the IL-5 and IL-13 pathway mediated by eotaxin 3 [39] and activating the T2 helper cell population. Studies of infliximab, mepolizumab, and CRTH2 antagonists have all shown insufficient clinical benefit for widespread use [40-42]. Initial studies on these antagonists have shown changes in the biological behavior of disease markers, but have not yet produced a generally applicable medical alternative to topical steroids. One of the difficulties in drug development has been the lack of a disease severity index and a poor prediction of the future likelihood of complicated EoE disease.

\section{Trials in Dietary Therapy}

Dietary therapy has not been so amenable to placebocontrolled clinical trials and has mostly been applied in the setting of childhood EoE. There is no clear consensus on when a diet is appropriate, and the current guidelines clearly state that immunology testing and food skin prick tests are not helpful in choosing which diet is suitable [43]. Dietary therapy needs careful support from experienced dieticians to ensure good nutrition, especially in growing children. Dietary therapy also creates difficulties in social development and normal behavior due to the restrictive effect of avoiding what are otherwise very normal foods in society. Harris et al. [44] addressed the need for psychological care and support to ensure a holistic approach to the care of children and adolescents with EoE.

\section{Dilatation}

At the moment there are no published controlled trials of dilatation therapy to guide the clinician in precisely when and how to perform esophageal dilatation for patients with EoE $[45,46]$. However, greater understanding of the role of dilatation and how it should be gauged is being developed.

\section{Conclusion}

EoE is now a well-established distinct disease about which much has been learned. It has become commonly diagnosed. EoE should be considered as one of the key differential diagnosis in any patient with a long-standing history of intermittent or continuous dysphagia. Since the description of this condition in case series in the early 1990s, the understanding of its pathobiology has increased and this continues with new understanding of its genetic profiling $[47,48]$. A limited number of randomized clinical trials have been performed. More needs to be done. It is expected that we will need a disease severity index that includes endoscopy, pathology, and clinical symptoms. Developing both adult and childhood EoE quality of life scores will be an important step in guiding treatment practices, preventing complications [49], improving disease education, and standardizing research protocols.

\section{Disclosure Statement}

The authors declare that no financial or other conflict of interest exists in relation to the content of the article. 


\section{References}

1 Landres RT, Kuster GG, Strum WB: Eosinophilic esophagitis in a patient with vigorous achalasia. Gastroenterology 1978;74:19281301.

$>2$ Picus D, Frank PH: Eosinophilic esophagitis. Am J Roentgenol 1981;136;1001-1003.

-3 Münch R, Kuhlmann U, Makeh M, et al: Eosinophilic esophagitis, a rare manifestation of eosinophilic gastroenteritis (in German). Schweiz Med Wochenschr 1982;112:731734.

4 Matzinger MA, Daneman A: Esophageal involvement in eosinophilic gastroenteritis. Pediatr Radiol 1983;13:35-38.

$\checkmark 5$ Feczko PJ, Halpert RD, Zonca M: Radiographic abnormalities in eosinophilic esophagitis. Gastrointest Radiol 1985; 10:321-324.

$\checkmark 6$ Lee RG: Marked eosinophilia in esophageal mucosal biopsies. Am J Surg Pathol 1985;9: 475-479.

$>7$ Attwood S, Smyrk T, deMeester T, Jones J: Esophageal eosinophilia with dysphagia. A distinct clinic pathological syndrome. Dig Dis Sci 1993;38;109-116.

$>8$ Straumann A, Spichtin HP, Bernoulli R, Loosli J, Vögtlin J: Idiopathic eosinophilic esophagitis: a frequently overlooked disease with typical clinical aspects and discrete endoscopic findings (in German). Schweiz Med Wochenschr 1994;124:1419-1429.

$\checkmark 9$ Kelly KJ, Lazenby AJ, Rowe PC, Yardley JH, Perman JA, Sampson HA: Eosinophilic oesophagitis attributed to gastroesophageal reflux, improvement with an amino acid-based formula. Gastroenterology 1995;109:15031512.

10 Straumann A, Spichtin HP, Grize L, et al: Natural history of primary eosinophilic esophagitis: a follow-up of 30 adult patients for up to 11.5 years. Gastroenterology 2003;125;16601669.

$>11$ Faubion WA Jr, Perrault J, Burgart LJ, Zein NN, Clawson M, Freese DK: Treatment of eosinophilic esophagitis with inhaled corticosteroids. J Pediatr Gastroenterol Nutr 1998; 27:90-93.

$>12$ Arora AS, Perrault J, Smyrk TC: Topical corticosteroid treatment of dysphagia due to eosinophilic esophagitis in adults. Mayo Clin Proc 2003;78:830-835.

$\checkmark 13$ Attwood SE, Lewis CJ, Bronder CS, Morris CD, Armstrong GR, Whittam J: Eosinophilic oesophagitis: a novel treatment using Montelukast. Gut 2003;52:181-185.

$>14$ Gupta SK, Fitzgerald JF, Chong SK, Croffie JM, Collins MH: Vertical lines in distal esophageal mucosa (VLEM): a true endoscopic manifestation of esophagitis in children? Gastrointest Endosc 1997;45:485-489.

15 Gonsalves N, Policarpio-Nicolas M, Zhang Q, Rao MS, Hirano I: Histopathologic variability and endoscopic correlates in adults with eosinophilic esophagitis. Gastrointest Endosc 2006;64:313-319.
16 Remedios M, Campbell C, Jones DM, Kerlin P: Eosinophilic esophagitis in adults: clinical, endoscopic, histologic findings, and response to treatment with fluticasone propionate. Gastrointest Endosc 2006;63:3-12.

17 Parfitt JR, Gregor JC, Suskin NG, Jawa HA, Driman DK: Eosinophilic esophagitis in adults: distinguishing features from gastroesophageal reflux disease: a study of 41 patients. Mod Pathol 2006;19:90-96.

18 Villarín LAJ, Carrión AG, Navarro Sánchez $\mathrm{M}$, et al: Eosinophilic esophagitis in adults, an emerging cause of dysphagia. Description of 9 cases. Rev Esp Enferm Dig 2005;97:229239.

19 Potter JW, Saeian K, Staff D, et al: Eosinophilic esophagitis in adults: an emerging problem with unique esophageal features. Gastrointest Endosc 2004;59:355-361.

$>20$ Kanakala V, Lamb CA, Haigh C, Stirling RW, Attwood SE: The diagnosis of primary eosinophilic oesophagitis in adults: missed or misinterpreted? Eur J Gastroenterol Hepatol 2010;22:848-855.

21 Kapel RC, Miller JK, Torres C, Aksoy S, Lash R, Katzka DA: Eosinophilic esophagitis: a prevalent disease in the United States that affects all age groups. Gastroenterology 2008; 134:1316-1321.

22 Lee S, de Boer WB, Naran A, Leslie C, Raftopoulous S, Ee H, Kumarasinghe MP: More than just counting eosinophils: proximal oesophageal involvement and subepithelial sclerosis are major diagnostic criteria for eosinophilic oesophagitis. J Clin Pathol 2010;63: 644-647.

23 Mueller S, Neureiter D, Aigner T, Stolte M: Comparison of histological parameters for the diagnosis of eosinophilic oesophagitis versus gastro-oesophageal reflux disease on oesophageal biopsy material. Histopathology 2008;53:676-684.

24 Furuta GT, Liacouras CA, Collins MH, et al: Eosinophilic esophagitis in children and adults: a systematic review and consensus recommendations for diagnosis and treatment. Gastroenterology 2007;133:1342-1363.

25 Liacouras CA, Furuta GT, Hirano I, Atkins D, Attwood SE, Bonis PA, et al: Eosinophilic esophagitis: updated consensus recommendations for children and adults. J Allergy Clin Immunol 2011;128:3-20.

26 Ronkainen J, Talley NJ, Aro P, et al: Prevalence of oesophageal eosinophils and eosinophilic oesophagitis in adults: the populationbased Kalixanda study. Gut 2007;56:615620.

27 Rodrigo S, Abboud G, Oh D, DeMeester SR, Hagen J, Lipham J, et al: High intraepithelial eosinophil counts in esophageal squamous epithelium are not specific for eosinophilic esophagitis in adults. J Gastroenterol 2008; 103:435-442.
28 Spechler SJ, Genta RM, Souza RF: Thoughts on the complex relationship between gastroesophageal reflux disease and eosinophilic esophagitis. Am J Gastroenterol 2007;102: 1301-1306.

29 Merwat SN, Spechler SJ: Might the use of acid-suppressive medications predispose to the development of eosinophilic esophagitis? Am J Gastroenterol 2009;104:1897-1902.

30 Attwood SE, Hatlebakk J, Fiocca R, et al: Defining eosinphilic infltration in gastroesophageal reflux disease using the LOTUS randomized controlled trial (abstract). Gastroenterology 2010;136:1142-1143.

-31 Galmiche JP, Hatlebakk J, Attwood S, et al: Laparoscopic antireflux surgery vs. esomeprazole treatment for chronic GERD: the LOTUS randomized clinical trial. JAMA 2011; 305:1969-1677.

32 Desai TK, Stecevic V, Chang CH, et al: Association of eosinophilic inflammation with esophageal food impaction in adults. Gastrointest Endosc 2005;61:795-801.

33 Hirano I: Editorial: should patients with suspected eosinophilic esophagitis undergo a therapeutic trial of proton pump inhibition? Am J Gastroenterol 2013;108:373-375.

34 Lamb CA, Kanakala V, Stirling RW, Attwood SE: Eosinophilic oesophagitis: a new diagnosis to swallow. Frontline Gastroenterol 2010; 1:25-29.

35 Attwood SE: Mechanisms underlying dysphagia in eosinophilic oesophagitis. Gut 2009; 58:1041-1042.

$>36$ Kwiatek MA, Hirano I, Kahrilas PJ, Rothe J, Luger D, Pandolfino JE: Mechanical properties of the esophagus in eosinophilic esophagitis. Gastroenterology 2011:140:82-90.

37 Straumann A, Conus S, Degen L, et al: Budesonide is effective in adolescent and adult patients with active eosinophilic esophagitis. Gastroenterology 2010;139:1526-1537.

38 Dohil R, Newbury R, Fox L, Bastian J, Aceves $\mathrm{S}$ : Oral viscous budesonide is effective in children with eosinophilic esophagitis in a randomized, placebo-controlled trial. Gastroenterology 2010;139:418-429.

39 Blanchard C, Wang N, Stringer KF, et al: Eotaxin-3 and a uniquely conserved gene-expression profile in eosinophilic esophagitis. J Clin Invest 2006;116;536-547.

40 Straumann A, Conus S, Grzonka P, et al: Anti-interleukin-5 antibody treatment (mepolizumab) in active eosinophilic oesophagitis: a randomised, placebo-controlled, doubleblind trial. Gut 2010;59:21-30.

41 Straumann A, Hoesli S, Bussmann Ch, et al: Anti-eosinophil activity and clinical efficacy of the CRTH2 antagonist OC000459 in eosinophilic esophagitis. Allergy 2013;68:375-385.

42 Dellon ES, Sheikh A, Speck O, et al: Viscous topical is more effective than nebulized steroid therapy for patients with eosinophilic esophagitis. Gastroenterology 2012;143:321324 
43 Spergel JM, Brown-Whitehorn TF, Cianferoni A, Shuker M, Wang ML, Verma R, Liacouras CA: Identification of causative foods in children with eosinophilic esophagitis treated with an elimination diet. J Allergy Clin Immunol 2012;130:461-467.

44 Harris RF, Menard-Katcher C, Atkins D, Furuta GT, Klinnert MD: Psychosocial dysfunction in children and adolescents with eosinophilic esophagitis. J Pediatr Gastroenterol Nutr 2013;57:500-505.

45 Dellon ES, Irani AM, Hill MR, Hirano I: Development and field testing of a novel patientreported outcome measure of dysphagia in patients with eosinophilic esophagitis. Aliment Pharmacol Ther 2013;38:634-642.

46 Nicodème F, Hirano I, Chen J, et al: Esophageal distensibility as a measure of disease severity in patients with eosinophilic esophagitis. Clin Gastroenterol Hepatol 2013;11: 1101-1107.
47 Noti M, Wojno ED, Kim BS, Siracusa MC, Giacomin PR, Nair MG, et al: Thymic stromal lymphopoietin-elicited basophil responses promote eosinophilic esophagitis. Nat Med 2013;19:1005-10013.

48 Wen T, Stucke EM, Grotjan TM, Kemme KA, Abonia JP, Putnam PE, et al: Molecular diagnosis of eosinophilic esophagitis by gene expression profiling. Gastroenterology 2013, Epub ahead of print.

49 Schoepfer AM, Safroneeva E, Bussmann C, Kuchen T, Portmann S, Simon HU, Straumann A: Delay in diagnosis of eosinophilic esophagitis increases risk for stricture formation, in a time-dependent manner. Gastroenterology 2013, E-pub ahead of print.
50 Straumann A, Spichtin HP, Bucher KA, et al: Eosinophilic esophagitis: red on microscopy, white on endoscopy. Digestion 2004;70:109116.

51 Alexandropoulou K, Ramakrishnan R, Chong $\mathrm{H}$, Finlayson C, Al Nasiri N, Poullis A, Kang J: Eosinophilic oesophagitis: gastro-oesophageal reflux disease interface. Gut 2009;58 (suppl 1):A113.

52 Collins MH, Blanchard C, Abonia JP, Kirby C, Akers R, Wang N, et al: Clinical, pathologic, and molecular characterization of familial eosinophilic esophagitis compared with sporadic cases. Clin Gastroenterol Hepatol 2008;6:621-629.

53 Assa'ad AH, Putnam PE, Collins MH, Akers RM, Jameson SC, Kirby CL, et al: Pediatric patients with eosinophilic esophagitis: an 8-year follow-up. J Allergy Clin Immunol 2007;119: 731-738. 